\title{
A case-control association study of COMT rs4680 Polymorphism with Obsessive-Compulsive Disorder and Cognitive Functions: The role of sex
}

sajedeh hamidian

university of social welfare and rehabilitation sciences https://orcid.org/0000-0001-5369-7014

Abbas Pourshahbaz

university of social welfare and rehabilitation sciences

atefeh moradkhani

Islamic Azad University Zanjan

Behrooz Dolatshahi

university of social welfare and rehabilitation sciences

Esmaeil Shahsavand Ananloo ( $\sim$ esmaeilshahsavand@gmail.com )

Tehran University of Medical Sciences

Mina Ohadi

university of social welfare and rehabilitation sciences

\section{Research article}

Keywords: Obsessive-compulsive disorder, rs4680 polymorphism, COMT gene, cognitive functions, Memory

Posted Date: June 19th, 2020

DOI: https://doi.org/10.21203/rs.3.rs-34240/v1

License: (c) (i) This work is licensed under a Creative Commons Attribution 4.0 International License. Read Full License 


\section{Abstract \\ Background}

Previous studies have emphasized the role of genetic components in obsessive-compulsive disorder (OCD) and cognitive functions. One of the most controversial markers in this area is the COMT rs4680 polymorphism. In the present study, we aimed to investigate the effect of rs 4680 on susceptibility to OCD and cognitive functions with respect to the moderating role of sex.

\section{Methods}

The subjects included 127 patients with OCD and 145 healthy controls. Genotyping was carried out by ARMS-PCR. The subjects underwent cognitive evaluations using the Wechsler Memory Scale-III. Data were analyzed using SPSS 22 and R package software.

\section{Results}

The results showed a significantly higher frequency of the AA genotype in the OCD group than in the healthy control group. Cognitive assessments showed weaker Immediate Memory and General Memory performance in the patients with OCD than in the control group. No significant association was found between rs 4680 and memory dimensions in the total sample, whereas analysis by sex revealed a significant association of rs 4680 with Working Memory only in females.

\section{Conclusions}

The results of this study confirm previous findings about the association of the AA genotype with OCD. These findings also corroborate previous assumptions about impaired episodic memory in patients with OCD. Moreover, the association of rs 4680 with Working Memory only in females endorses the hypothesis of the sexual dimorphism of the effects of this COMT gene polymorphism.

\section{Introduction}

Obsessive-compulsive disorder (OCD) is a debilitating neuropsychiatric mental disorder characterized by disturbing intrusive thoughts (obsessions) and/or repetitive and persistent behaviors (compulsions) and is defined by the concept of coercion(1).

Genetic factors play a significant role in the development of OCD, as the incidence rate among the first-degree relatives of patients with OCD is five to ten times greater than that of the general population(2). OCD has been related to the functioning of several genes; however, association studies that looked for candidate genes in OCD mostly obtained inconsistent results $(3,4)$.

One of the highly regarded genes is the catechol-0-methyltransferase (COMT) gene. The most widely studied polymorphism of this gene is rs4680 (also known as Val158Met), which is a functional polymorphism leading to an exchange of valine (Val) for methionine (Met). This replacement increases the activity of the enzyme, by 3 or 4 times, through which dopamine is regulated in the central nervous system, particularly in the prefrontal cortex (PFC). Since dopamine dysregulation is implicated in the pathogenesis of OCD, variations in rs 4680 genotypes might be candidate markers for the recognition of predisposition to OCD.

Regarding the association of COMT with OCD, some of the studies have reported an association of the Met allele with OCD only in men(5-8), while Alsobrook et al (2002) found the Met allele association with OCD only in women(9). A meta-analysis by Azzam and Mathews (2003) reported a significant association of rs4680 with OCD in a sample of men and women, whereas a metaanalysis by Pooley et al (2007) found the same association only in men(7). On the other hand, there are studies that reported no association between rs4680 genotypes and $\mathrm{OCD}(10-12)$. 
In terms of neuropsychological approaches, OCD is comorbid with a variety of cognitive impairments (13). Numerous studies have focused on the impairment of episodic memory, including verbal and nonverbal memory, and working memory in OCD (14). Animal and human studies have also pointed out dysregulations in a brain network, including the hippocampal formation (HF) and the ventrolateral prefrontal cortex (VLPFC)(15), which initiates processes that support declarative memory components such as episodic and semantic encoding and retrieval(16). Dopamine, as one of the main neurotransmitters, regulates memory functions such as episodic memory and long-term potentiation in these regions $(17,18)$. Therefore, genes regulating the dopaminergic system appear to be suitable candidates for association with cognitive functions such as memory(19).

Recent studies have demonstrated the role of COMT allelic variants in memory functions (20); however, the relationship between the rs4680 polymorphism and different aspects of memory has been controversial. The association of the Met allele with increased hippocampal activity and better performance in declarative and working memory has been suggested $(1,24-26)$. The Val allele has also been suggested to be associated with greater cognitive flexibility(20) and increased VLPFC activity during memory tasks(21).

The other group of studies has reported the lack of a relationship between COMT and working memory functions in both healthy and psychiatric populations(22-25). Consequently, the relationship between the rs 4680 polymorphism and memory functions seems to be heterogeneous and hard to integrate.

Furthermore, sex differences in many psychiatric disorders, including OCD, are one of the complicating factors in genetic studies. There is evidence that predominant genes that determine sex differences might also play a role in the differing clinical phenotypes between the two sexes. COMT is one of those genes that exhibits sexual dimorphism associated with clinical phenotypes(26). COMT enzymatic activity in the peripheral cortex and liver was shown to be higher in men than in women(27). Therefore, it could be expected that the pattern of COMT association with OCD and cognitive functions may also follow a sexual dimorphism.

Overall, given the role of the COMT rs4680 polymorphism in dopamine metabolism and the role of the dopamine system in OCD and its related cognitive deficits, such as memory, the objectives of the present study were to investigate 1) the association of the rs4680 polymorphism with OCD, 2) whether the rs4680 polymorphism is associated with memory dimensions and 3) the sexspecific impact of the rs 4680 genotype on OCD and the functioning of memory dimensions.

\section{Methods}

\section{Study design and participants:}

In the present case-control association study, two hundred and seventy-two Iranian participants, including 127 unrelated patients with OCD and 145 healthy controls, were evaluated. The patient group was diagnosed with OCD according to the Diagnostic and Statistical Manual of Mental Disorders; Fifth Edition (DSM-V) by an expert psychiatrist. They were enrolled in the study provided that they fulfilled the following criteria: age between 18 and 60 years and OCD diagnosis as the primary diagnosis. The exclusion criteria were as follows: 1) the diagnosis of current or a lifetime history of another mental disorder; 2) current or lifetime history of neurological disorders; 3) substance and alcohol dependency; and 4) a history of head trauma, epilepsy or surgery in the past two weeks and a history of electroconvulsive therapy (ECT) in the last 6 months. All of the OCD group had been taking psychotropic medications. The control group was selected through purposeful sampling and was matched to the case group for age, sex and years of education and had no current or previous history of psychiatric or neurological disorders.

\section{Measures:}

\section{Wechsler Memory Scale-III (WMS-III)}

The Wechsler Memory Scale-III (WMS-III) is a comprehensive measure of memory and contains 11 primary subscales. Three main indexes obtained from the primary subscales are Immediate Memory, General Memory (which is known as an index of episodic memory), and Working Memory. Cronbach's alpha results of the Persian version of this scale varied between 0.75 for Delayed Auditory Recognition to 0.86 for General Memory(28).

The Yale-Brown Obsessive-Compulsive Scale (Y-BOCS)

Page 3/11 
This scale is a semistructured interview for assessments of the severity of obsessive-compulsive (OC) symptoms. It consists of 10 questions in two parts on obsessions and compulsions. The Persian version reported a test-retest reliability of 0.99 and an internal consistency score of $0.95(29)$.

\section{Beck Depression Inventory-2 (BDI-II)}

This is a 21-item self-report inventory for measurements of depression severity. The reliability coefficient of this inventory for an Iranian population was reported to be $0.913(30)$.

\section{Hamilton Anxiety Rating Scale (HARS)}

This scale is used to evaluate the severity of anxiety and consists of 14 items. The reliability of this scale was reported by Haghshenas (1990) through test-retest reliability as 0.81 (9)

\section{DNA Preparation and Genotyping}

Five milliliters of venous blood was collected into a tube containing EDTA. Genomic DNA was extracted using a salting-out procedure and stored at $-20^{\circ} \mathrm{C}$ for genotype analysis.

Genotyping was performed using amplification refractory mutation system-polymerase chain reaction (ARMS-PCR). The PCRs were carried out in a total volume of $10 \mu \mathrm{L}$ containing $5 \mu \mathrm{L}$ of master mix (MgCl2 $1.5 \mathrm{M}$ ), $3.5 \mu \mathrm{L}$ nuclease-free water, $0.5 \mu \mathrm{L}$ template DNA, $0.5 \mu \mathrm{L}$ forward outer (FO) primer and $0.5 \mu \mathrm{L}$ reverse normal (RN) or reverse mutant (RM) primer. For each sample, PCR was performed twice, once using FO-RN primers and another time with FO-RM primers. Any unequivocal result was resolved by repeating genotyping.

ARMS-PCR uses two pairs of primers to amplify two different alleles of a single-nucleotide polymorphism (SNP) in a single PCR. The region flanking the SNP is amplified by two outer (nonallele-specific) primers as well as two inner (allele-specific) primers that are designed in the opposite orientation of the outer primers. The two inner amplicons have visibly distinct lengths that allow easy identification by agarose gel electrophoresis. Primers were designed using a combination of PRIMER1 online software and Gene Runner software. To increase the specificity of the reaction, a mismatch at position - 2 from the 3 ' end is introduced for the two allele-specific primers. The BLAST program was utilized to check the specificity of the designed primers and their melting temperatures (http://www.ncbi.nlm.nih.gov/blast). The sequences of the primers used are provided in Table 1.

Table 1

PCR primers and conditions used for the COMT rs4680 polymorphism

\begin{tabular}{|lllll|}
\hline Primer sequence 5'-3' $^{\prime}$ & Length & GC Percentage & Annealing Temperature (C) & Amplicon Size \\
\hline FO = GTGATTCAGGAGCACCAGCCCTCC & $24 \mathrm{bp}$ & $63 \%$ & $69 / 88$ & $69 / 88$ \\
\hline RO = TCCTGGTGCCACCTTGGCAGTTTAC & $25 \mathrm{bp}$ & $56 \%$ & $69 / 64$ & $69 / 64$ \\
\hline RN = CAGGCATGCACACCTTGTCCTTCAC & $25 \mathrm{bp}$ & $56 \%$ & $69 / 58$ & $69 / 58$ \\
\hline RM = CAGGCATGCACACCTTGTCCTTCAT & $25 \mathrm{bp}$ & $52 \%$ & $68 / 98$ & $68 / 98$ \\
\hline FO: forward outer RU: reverse outer; RN: reverse normal; RM: reverse mutant & \\
\hline
\end{tabular}

\section{Statistical Analysis}

R statistical package and SPSS software version 22 were used for data analysis. The $\chi 2$ test was used for the analysis of genotype and allele frequencies between the case group and the control group. The $\chi 2$ and independent-sample t-test were also used to compare the two groups in terms of demographic variables. Genotype-phenotype correlations were investigated using an analysis of covariance (ANCOVA) to test the effect of having OCD (Group), genotype variations (Genotype) and Group-Genotype interaction on memory dimensions while controlling for depression and anxiety as covariate variables. The statistical significance level for all tests was set as $\mathrm{P}<0.05$.

\section{Results}




\section{Demographic and Clinical characteristics of the OCD and control groups}

The results of assessments of demographic variables showed that the OCD and control groups did not differ significantly in terms of mean age $(p=0.27, t=1.09)$, sex distribution $(p=0.2$, chi squared $=57.17)$ or handedness $(p=0.32$, chi squared $=0.97)$. There were also no significant differences in education level $(p=0.31$, chi squared $=87.5)$ or ethnicity $(p=0.09$, chi squared $=6.34)$. Therefore, we assume that the moderating effect of these variables has been controlled. For the clinical variables of the OCD and control groups, the mean score of depression was 18.7 and 4.7, respectively, and the mean score of anxiety was 15.6 and 4.9 , respectively. Among the OCD participants, the mean severity score of the Y-BOCS for obsessions and compulsions and the total score were 12.7, 12.5 and 25.3, respectively, which means moderate severity.

\section{SNP Analysis for OCD}

Table 2

Allele and genotype frequency for rs 4680 in the OCD and control groups for the total sample and for males and females

\begin{tabular}{|c|c|c|c|c|c|c|}
\hline \multirow[t]{2}{*}{ Group } & & & OCD & Control & \multirow[t]{2}{*}{ Chi squared } & \multirow[t]{2}{*}{$P$ value } \\
\hline & & & $\mathrm{N}(\%)$ & $\mathrm{N}(\%)$ & & \\
\hline \multirow[t]{5}{*}{ Total } & \multirow[t]{2}{*}{ Allele } & $A$ & $135(53.1 \%)$ & $130(44.8 \%)$ & \multirow[t]{2}{*}{3.75} & \multirow[t]{2}{*}{0.052} \\
\hline & & $\mathrm{G}$ & $119(46.8 \%)$ & 160 (55.2\%) & & \\
\hline & \multirow[t]{3}{*}{ Genotype } & $\mathrm{AA}$ & $20(15.7 \%)$ & $9(6.2 \%)$ & \multirow[t]{3}{*}{8.41} & \multirow[t]{3}{*}{$0.014^{*}$} \\
\hline & & GG & $12(9.4 \%)$ & $24(16.6 \%)$ & & \\
\hline & & $A G$ & $95(74.8 \%)$ & $112(77.2 \%)$ & & \\
\hline \multirow[t]{5}{*}{ Female } & \multirow[t]{2}{*}{ Allele } & $A$ & $84(53.1 \%)$ & $72(44.4 \%)$ & \multirow[t]{2}{*}{2.1} & \multirow[t]{2}{*}{0.14} \\
\hline & & $\mathrm{G}$ & $74(46.8 \%)$ & $88(54.3 \%)$ & & \\
\hline & \multirow[t]{3}{*}{ Genotype } & $\mathrm{AA}$ & $13(16.4 \%)$ & $4(4.9 \%)$ & \multirow[t]{3}{*}{5.73} & \multirow[t]{3}{*}{0.056} \\
\hline & & GG & $8(10.1 \%)$ & $11(13.5 \%)$ & & \\
\hline & & $A G$ & $(73.4 \%) 58$ & $66(81 \%)$ & & \\
\hline \multirow[t]{5}{*}{ Male } & \multirow[t]{2}{*}{ Allele } & $A$ & $51(53.1 \%)$ & $56(43.7 \%)$ & \multirow[t]{2}{*}{1.93} & \multirow[t]{2}{*}{0.16} \\
\hline & & $G$ & $45(46.8 \%)$ & $72(56.2 \%)$ & & \\
\hline & \multirow[t]{3}{*}{ Genotype } & $\mathrm{AA}$ & $7(14.5 \%)$ & $5(7.8 \%)$ & \multirow[t]{3}{*}{3.86} & \multirow[t]{3}{*}{0.14} \\
\hline & & GG & $4(8.3 \%)$ & $13(20 \%)$ & & \\
\hline & & $A G$ & 37 (77\%) & $46(71 \%)$ & & \\
\hline \multicolumn{7}{|c|}{ * Significant effect } \\
\hline \multicolumn{7}{|c|}{$\begin{array}{l}\text { As depicted in Table 2, the frequencies of the } A \text { and } G \text { alleles in the } O C D \text { and control groups were not significantly different. } \\
\text { The distribution of genotype frequency showed significant differences between the OCD and control groups. Post hoc analysis } \\
\text { showed that the observed difference was due to the significant difference in AA genotype frequency (chi squared = } 6.47 ; P= \\
0.01 \text { ) between the two groups, which confirms a recessive genetic model for the association of rs } 4680 \text { with OCD. Stratification } \\
\text { for sex showed that the allele frequency was not significantly different between the sexes. Regarding the genotypic frequency, } \\
\text { the results did not show significant differences in males and females; however, in females, a trend could be suggested (chi } \\
\text { squared }=5.73 ; P=0.056 \text { ). }\end{array}$} \\
\hline
\end{tabular}

SNP Analysis for Memory dimensions 
Table 3

The results of the ANCOVA on the effect of groups, genotypes and their interaction on memory dimensions

\begin{tabular}{|c|c|c|c|c|c|c|c|c|c|c|c|c|}
\hline & $\mathrm{F}$ & $P$ & Eta & $F$ & $\mathbf{P}$ & Eta & $\mathrm{F}$ & $\mathbf{P}$ & Eta & $F$ & $\mathbf{P}$ & Eta \\
\hline & \multicolumn{3}{|c|}{$\begin{array}{l}\text { Audio Immediate } \\
\text { Memory }\end{array}$} & \multicolumn{3}{|c|}{ Visual Immediate Memory } & \multicolumn{3}{|c|}{ Immediate Memory } & \multicolumn{3}{|c|}{$\begin{array}{l}\text { Audio Delayed } \\
\text { Memory }\end{array}$} \\
\hline Group & 7.28 & 0.008 & 0.04 & 5.42 & 0.02 & 0.03 & 7.62 & 0.006 & 0.04 & 4.86 & 0.02 & 0.02 \\
\hline Genotype & 0.09 & 0.90 & 0.001 & 0.55 & 0.57 & 0.006 & 0.04 & 0.95 & 0.000 & 0.04 & 0.95 & 0.001 \\
\hline \multirow{2}{*}{$\begin{array}{l}\text { Group } x \\
\text { Genotype }\end{array}$} & 1.05 & 0.35 & 0.01 & 0.57 & 0.56 & 0.007 & 1.25 & 0.28 & 0.01 & 0.26 & 0.76 & 0.003 \\
\hline & \multicolumn{3}{|c|}{$\begin{array}{l}\text { Visual Delayed } \\
\text { Memory }\end{array}$} & \multicolumn{3}{|c|}{$\begin{array}{l}\text { Audio Recognition Delayed } \\
\text { Memory }\end{array}$} & \multicolumn{3}{|c|}{ General Memory } & \multicolumn{3}{|c|}{ Working Memory } \\
\hline Group & 9.04 & 0.003 & 0.04 & 0.64 & 0.42 & 0.004 & 8.67 & 0.004 & & 3.10 & 0.08 & 0.01 \\
\hline Genotype & 0.24 & 0.78 & 0.003 & 0.26 & 0.76 & 0.003 & 0.003 & 0.99 & 0.000 & 1.91 & 0.15 & 0.02 \\
\hline $\begin{array}{l}\text { Group } x \\
\text { Genotype }\end{array}$ & 0.71 & 0.48 & 0.008 & 0.38 & 0.68 & 0.004 & 1.43 & 0.24 & 0.01 & 0.91 & 0.40 & 0.01 \\
\hline
\end{tabular}

Table 3 shows the results of the ANCOVA on memory dimensions. In the subscales, Audio and Visual Immediate Memory and Audio and Visual Delayed Memory showed significantly weaker performance in the OCD group than in the control group. Among the memory indexes, the Immediate and General Memory performance of the total sample were significantly weaker among the OCD group. The results of the ANCOVA for genotype analysis did not find Genotype or Group-Genotype interaction effects on any of the memory dimensions. 
Table 4

The results of the ANCOVA on the effect of groups, genotypes and their interaction on memory dimensions in males and females

\begin{tabular}{|c|c|c|c|c|c|c|c|c|c|c|c|c|c|}
\hline $\operatorname{sex}$ & Factor & $\mathbf{F}$ & $P$ & Eta & $\mathbf{F}$ & $\mathbf{P}$ & Eta & $\mathbf{F}$ & $\mathbf{P}$ & Eta & $\mathbf{F}$ & $\mathbf{P}$ & Eta \\
\hline \multirow[t]{8}{*}{ Female } & & \multicolumn{3}{|c|}{$\begin{array}{l}\text { Audio Immediate } \\
\text { Memory }\end{array}$} & \multicolumn{3}{|c|}{$\begin{array}{l}\text { Visual Immediate } \\
\text { Memory }\end{array}$} & \multicolumn{3}{|c|}{ Immediate Memory } & \multicolumn{3}{|c|}{$\begin{array}{l}\text { Audio Delayed } \\
\text { Memory }\end{array}$} \\
\hline & Group & 4.71 & 0.03 & 0.04 & 9.5 & 0.003 & 0.08 & 9.37 & 0.003 & 0.08 & 5.73 & 0.01 & 0.05 \\
\hline & Genotype & 0.53 & 0.58 & 0.01 & 1.31 & 0.27 & 0.02 & 0.40 & 0.67 & 0.007 & 0.02 & 0.97 & 0.000 \\
\hline & $\begin{array}{l}\text { Group x } \\
\text { Genotype }\end{array}$ & 2.12 & 0.12 & 0.03 & 1.08 & 0.34 & 0.02 & 1.90 & 0.15 & 0.03 & 1.12 & 0.33 & 0.02 \\
\hline & & \multicolumn{3}{|c|}{ Visual Delayed Memory } & \multicolumn{3}{|c|}{$\begin{array}{l}\text { Audio Recognition } \\
\text { Delayed Memory }\end{array}$} & \multicolumn{3}{|c|}{ General Memory } & \multicolumn{3}{|c|}{ Working Memory } \\
\hline & Group & 12.55 & 0.001 & 0.10 & 0.78 & 0.37 & 0.007 & 9.65 & 0.002 & 0.08 & 4.22 & 0.04 & 0.03 \\
\hline & Genotype & 0.48 & 0.61 & 0.009 & 0.31 & 0.72 & 0.006 & 0.09 & 0.93 & 0.002 & 4.26 & 0.01 & 0.07 \\
\hline & $\begin{array}{l}\text { Group x } \\
\text { Genotype }\end{array}$ & 2.89 & 0.06 & 0.05 & 0.48 & 0.62 & 0.009 & 3.07 & 0.05 & 0.05 & 1.59 & 0.20 & 0.02 \\
\hline \multirow[t]{8}{*}{ Male } & & \multicolumn{3}{|c|}{$\begin{array}{l}\text { Audio Immediate } \\
\text { Memory }\end{array}$} & \multicolumn{3}{|c|}{$\begin{array}{l}\text { Visual Immediate } \\
\text { Memory }\end{array}$} & \multicolumn{3}{|c|}{ Immediate Memory } & \multicolumn{3}{|c|}{$\begin{array}{l}\text { Audio Delayed } \\
\text { Memory }\end{array}$} \\
\hline & Group & 4.07 & 0.04 & 0.05 & 0.32 & 0.57 & 0.004 & 1.92 & 0.16 & 0.02 & 2.84 & 0.09 & 0.03 \\
\hline & Genotype & 0.68 & 0.50 & 0.01 & 1.14 & 0.32 & 0.03 & 1.25 & 0.29 & 0.03 & 1.17 & 0.31 & 0.03 \\
\hline & $\begin{array}{l}\text { Group x } \\
\text { Genotype }\end{array}$ & 0.14 & 0.86 & 0.004 & 20090 & 0.21 & 0.04 & 1.23 & 0.29 & 0.03 & 0.80 & 0.45 & 0.02 \\
\hline & & \multicolumn{3}{|c|}{ Visual Delayed Memory } & \multicolumn{3}{|c|}{$\begin{array}{l}\text { Audio Recognition } \\
\text { Delayed Memory }\end{array}$} & \multicolumn{3}{|c|}{ General Memory } & \multicolumn{3}{|c|}{ Working Memory } \\
\hline & Group & 2.21 & 0.14 & 0.03 & 0.23 & 0.62 & 0.003 & 3.76 & 0.05 & 0.05 & 0.44 & 0.50 & 0.006 \\
\hline & Genotype & 0.71 & 0.49 & 0.01 & 2.48 & 0.09 & 0.06 & 1.78 & 0.17 & 0.04 & 0.72 & 0.49 & 0.02 \\
\hline & $\begin{array}{l}\text { Group x } \\
\text { Genotype }\end{array}$ & 1.05 & 0.35 & 0.02 & 0.19 & 0.82 & 0.005 & 1.28 & 0.28 & 0.03 & 1.06 & 0.35 & 0.02 \\
\hline
\end{tabular}

Table 4 shows the results of comparing memory functions between the females and males of the two study groups. For the females, the memory subscales performances in the two groups showed a similar pattern with the total sample. In the memory indexes, a significantly weaker performance of the three indexes was observed for the OCD group, which means weaker working and episodic memory performance of female patients with OCD than of healthy individuals. In the male group, the results showed that the Audio Immediate Memory was significantly impaired in the OCD group. The results of the ANCOVA showed no significant effect of genotypes on memory subscales for either sex. Of the memory indexes, a significant effect of genotype on Working Memory was observed in females. However, the Group-Genotype interaction had a slight (suggestive) effect on the General Memory index. Regarding the indexes in males, no significant effect of Genotype or Group-Genotype interaction was detected on the memory indexes.

\section{Discussion}

The results of the present study replicated the association between the Met/Met genotype of COMT and an increased risk of OCD. This finding is in line with the studies of Niehaus et al. (2001), Karaiyorgou et al. (1997), Denys et al. (2006), Pooley et al. (2007), and Katerberg et al $(4-6,31,32)$; however, in some studies, the association has been reported only in men $(6,32)$. The findings are inconsistent with the association studies of Ohara et al. (1998)(33), Meira-Lima et al. (2004)(11), Tukel et al. (2013)(34) and Sampaio et al. (2015)(35). 
To illustrate the heterogeneous results of the studies, the effect of ethnicity could be considered. Studies have suggested that the effect of this polymorphism is stronger in some ethnicities than in others. The Met/Met genotype correlates with lower COMT gene activity, which results in a reduced amount of COMT enzyme and subsequently causes lower dopamine degradation, resulting in a hyperdopaminergic state that may be involved in the pathogenesis of OCD $(36,37)$. Consistent with the present results, Denys et al. (2006) suggested that patients with a low COMT activity genotype may have longer and more effective dopamine release that might be more vulnerable to the development of OC symptoms(5).

For the memory dimensions, audio and visual memory retrieval were more defective in patients with OCD than in the control group. Moreover, both the Immediate and General Memory indexes showed weaker performance in the OCD group, although significantly weaker Working Memory was observed only among females. The results of this study supported the hypotheses about poorer performance of patients with OCD in episodic memory than of healthy controls. Although the research literature on memory performance has mainly focused on nonverbal memory impairments $(9,10)$, our data present impairments in both verbal and nonverbal memory functions. According to the neuropsychological findings, if we assume that patients with OCD suffer from disturbances in organizational and semantic strategies used during encoding and learning, they are expected to exhibit similar problems in both verbal and nonverbal areas (19), an assumption that was confirmed by our findings. Patients with OCD tend to focus on the unrelated details of the objects; hence, the observed memory impairments in these patients can be explained by Savage et al. (1999), who suggested that when attention to details is overwhelming, it can prevent proper understanding of contextual information and regarding it as a whole, thereby resulting in retrieval deficits (38).

Previous studies on working memory revealed a discordant pattern. Martoni et al. suggested that working memory becomes more defective as task becomes more complex and difficult because of the increased need to keep unrelated information in mind and the use of memory management strategies. (35). Therefore, since the Working Memory task in this study was letter-number sequencing and spatial span, which are categorized as complex tasks, the observed result in females was expected; however, the dissimilar functions in males and females may suggest different mechanisms underlying episodic and working memory in both sexes. Another interesting hypothesis for weaker working memory in patients with OCD is that part of the patients' working memory is kept occupied by their obsessions and ruminations, which reduces the processing capacity available for the other tasks.

Regarding sex-related genotype analysis, the results showed an association of COMT genotypes with Working Memory only in females. The results of the descriptive analysis for Working Memory performance revealed that females with the Val/Val genotype had the weakest, those with the Met/Met genotype had moderate, and those with the Val/Met genotype had the best performance. These results are consistent with the inverted $U$ shape theory for dopamine in OCD that states that COMT homozygotes exhibit the worst and the best and heterozygotes exhibit moderate performance in cognitive functions.

As mentioned earlier, there are numerous reports that describe the sexual dimorphism of COMT activity(26). This dimorphism has also been reported for cognitive functions $(20,39)$. To illustrate the sex-related effect of COMT, the role of estrogen is usually discussed. Xie et al. (1999) showed that there are two elements of the estrogen response in the COMT gene promoter and that estradiol at high physiological concentrations inhibits mRNA expression of COMT, leading to a relative decrease in activity and the expression of COMT(40). This inhibition by estrogens is consistent with the sex differences observed in COMT activity.

Hippocampal and hepatic COMT enzyme levels were found to be lower in females than in males(9). Thus, women who inherit one or two alleles for the low-activity COMT isoform may have even lower levels of hippocampal enzyme activity than men with the same alleles. Given the important role suggested for the hippocampus in memory functions, this decrease in activity by affecting dopamine regulation might explain the different effects of COMT on the memory functions of men and women.

Therefore, it may be concluded that the rs 4680 polymorphism is a susceptibility factor for OCD and female memory functioning. Met homozygosity could be a risk factor for OCD and predict better working memory functioning, while Val homozygosity is associated with worse episodic memory and working memory functioning in female patients with OCD.

\section{Declarations}

\section{Ethics approval and consent to participate}


After the explanation about the project, the participants signed an informed consent form before entering the study. The present study was approved by the University of Social Welfare and Rehabilitation Sciences (USWR) ethical committee with the code Ir.uswr.rec.1396.216.

\section{Consent for publication}

Not applicable

\section{Availability of data and materials}

The datasets used and/or analysed during the current study are available from the corresponding author on reasonable request.

\section{Competing interests}

The authors declare that they have no competing interests.

\section{Funding}

The present study was received any financial support.

\section{Authors' contributions}

SH was involved in gathering psychometric data, analyzing data and writing the manuscript. ESH cooperated in concept of the study, data acquisition and preparing the manuscript. AP presented design of the study and statistical analysis. AM performed DNA extraction and genotyping. BD cooperated in literature search. MO was involved in data interpretation and manuscript writing and editing. All authors read and approved the final manuscript.

\section{Acknowledgments}

We thank all the patients who contributed to this study and declare that the present study has not received any financial support.

\section{References}

1. Umehara H, Numata S, Kinoshita M, Watanabe S, Nakaaki S, Sumitani S, et al. No association between BDNF Val66Met polymorphism and treatment response in obsessive-compulsive disorder in the Japanese population. Neuropsychiatr Dis Treat. 2016;12:611-5.

2. Browne HA, Gair SL, Scharf JM, Grice DE. Genetics of Obsessive-Compulsive Disorder and Related Disorders. Psychiatr Clin North Am. 2014;37(3):319-35.

3. Markarian Y, Larson MJ, Aldea MA, Baldwin SA, Good D, Berkeljon A, et al. Multiple pathways to functional impairment in obsessive-compulsive disorder. Clin Psychol Rev. 2010;30(1):78-88.

4. Katerberg H, Lochner C, Cath DC, de Jonge P, Bochdanovits Z, Moolman-Smook JC, et al. The role of the brain-derived neurotrophic factor (BDNF) val66met variant in the phenotypic expression of obsessive-compulsive disorder (OCD). American Journal of Medical Genetics Part B: Neuropsychiatric Genetics. 2009;150(8):1050-62.

5. Denys D, Van Nieuwerburgh F, Deforce D, Westenberg H. Association between the dopamine D2 receptor Taql A2 allele and low activity COMT allele with obsessive-compulsive disorder in males. Eur Neuropsychopharmacol. 2006;16(6):446-50.

6. Pooley E, Fineberg N, Harrison P. The met158 allele of catechol-0-methyltransferase (COMT) is associated with obsessivecompulsive disorder in men: case-control study and meta-analysis. Molecular psychiatry. 2007;12(6):556-61.

7. Katerberg H, Cath DC, Denys DA, Heutink P, Polman A, van Nieuwerburgh FC, et al. The role of the COMT Val158Met polymorphism in the phenotypic expression of obsessive-compulsive disorder. American Journal of Medical Genetics Part B: 
Neuropsychiatric Genetics. 2010;153(1):167-76.

8. Karayiorgou M, Altemus M, Galke BL, Goldman D, Murphy DL, Ott J, et al. Genotype determining low catechol-Omethyltransferase activity as a risk factor for obsessive-compulsive disorder. Proceedings of the National Academy of Sciences. 1997;94(9):4572-5.

9. Alsobrook JP, Zohar AH, Leboyer M, Chabane N, Ebstein RP, Pauls DL. Association between the COMT locus and obsessivecompulsive disorder in females but not males. Am J Med Genet. 2002;114(1):116-20.

10. Erdal ME, Tot Ş, Yazıcı K, Yazıcı A, Herken H, Erdem P, et al. Lack of Association of catechol-O-Methyltransferase Gene Polymorphism in Obsessive-Compulsive Disorder. Depress Anxiety. 2003;18(1):41-5.

11. Meira-Lima I, Shavitt R, Miguita K, Ikenaga E, Miguel E, Vallada H. Association analysis of the catechol-o-methyltransferase (COMT), serotonin transporter (5-HTT) and serotonin 2A receptor (5HT2A) gene polymorphisms with obsessive-compulsive disorder. Genes Brain Behavior. 2004;3(2):75-9.

12. Schindler KM, Richter M, Kennedy JL, Pato MT, Pato CN. Association between homozygosity at the COMT gene locus and obsessive compulsive disorder. Am J Med Genet. 2000;96(6):721-4.

13. Kashyap H, Kumar JK, Kandavel T, Reddy YJ. Neuropsychological functioning in obsessive-compulsive disorder: are executive functions the key deficit? Compr Psychiatry. 2013;54(5):533-40.

14. Nakamae T, Narumoto J, Sakai Y, Nishida S, Yamada K, Fukui K. The neural basis of dysfunctional beliefs in non-medicated patients with obsessive-compulsive disorder. Prog Neuropsychopharmacol Biol Psychiatry. 2012;37(1):22-5.

15. Bertolino A, Rubino V, Sambataro F, Blasi G, Latorre V, Fazio L, et al. Prefrontal-hippocampal coupling during memory processing is modulated by COMT val158met genotype. Biol Psychiatry. 2006;60(11):1250-8.

16. Krach S, Jansen A, Krug A, Markov V, Thimm M, Sheldrick AJ, et al. COMT genotype and its role on hippocampal-prefrontal regions in declarative memory. Neuroimage. 2010;53(3):978-84.

17. Grant JE, Leppink EW, Redden SA, Odlaug BL, Chamberlain SR. COMT genotype, gambling activity, and cognition. J Psychiatr Res. 2015;68:371-6.

18. Lopez-Garcia P, Espinoza LY, Santos PM, Marin J, Sanchez-Pedreño FO. Impact of COMT genotype on cognition in schizophrenia spectrum patients and their relatives. Psychiatry research. 2013;208(2):118-24.

19. Schott BH, Seidenbecher Cl, Fenker DB, Lauer CJ, Bunzeck N, Bernstein H-G, et al. The dopaminergic midbrain participates in human episodic memory formation: evidence from genetic imaging. J Neurosci. 2006;26(5):1407-17.

20. Gurvich C, Rossell S. Dopamine and cognitive control: sex-by-genotype interactions influence the capacity to switch attention. Behav Brain Res. 2015;281:96-101.

21. Bertolino A, Caforio G, Petruzzella V, Latorre V, Rubino V, Dimalta S, et al. Prefrontal dysfunction in schizophrenia controlling for COMT Val158Met genotype and working memory performance. Psychiatry Research: Neuroimaging. 2006;147(2-3):2216.

22. Zilles D, Meyer J, Schneider-Axmann T, Ekawardhani S, Gruber E, Falkai P, et al. Genetic polymorphisms of 5-HTT and DAT but not COMT differentially affect verbal and visuospatial working memory functioning. Eur Arch Psychiatry Clin NeuroSci. 2012;262(8):667-76.

23. Mills S, Langley K, Van den Bree M, Street E, Turic D, Owen MJ, et al. No evidence of association between Catechol-OMethyltransferase (COMT) Val 158 Met genotype and performance on neuropsychological tasks in children with ADHD: A case-control study. BMC Psychiatry. 2004;4(1):15.

24. Wardle MC, de Wit H, Penton-Voak I, Lewis G, Munafo MR. Lack of association between COMT and working memory in a population-based cohort of healthy young adults. Neuropsychopharmacology. 2013;38(7):1253-63.

25. Geller S, Wilhelm O, Wacker J, Hamm A, Hildebrandt A. Associations of the COMT Val158Met polymorphism with working memory and intelligence-A review and meta-analysis. Intelligence. 2017;65:75-92.

26. Harrison PJ, Tunbridge EM. Catechol-O-methyltransferase (COMT): a gene contributing to sex differences in brain function, and to sexual dimorphism in the predisposition to psychiatric disorders. Neuropsychopharmacology. 2008;33(13):3037.

27. Kinnear C, Niehaus D, Seedat S, Moolman-Smook J, Corfield V, Malherbe G, et al. Obsessive-compulsive disorder and a novel polymorphism adjacent to the oestrogen response element (ERE 6) upstream from the COMT gene. Psychiatr Genet. 
2001;11(2):85-7.

28. Saed O, Roshan R. Practical Guide to the Iranian Version of the Wechsler Memory Scale (WMS-III). Tehran: Olum raftarishenakhsti sina; 2016.

29. Assarian F, Ghoreishi FS, Borna M, Razzaghof M. The Efficacy of Aripiprazole versus Risperidone as Augmentation Therapy in Treatment-Resistant Obsessive-Compulsive Disorder: A Double Blind Clinical Trial. Iranian Red Crescent Medical Journal. 2016(In Press).

30. Mohammadkhani p. Dobson k. Psychometric coordinates of BDI-II in a large sample of the patients with major depression. Rehabilitation in psychological diseases and disorders. 2007.

31. Niehaus D, Kinnear C, Corfield V, Du Toit P, Van Kradenburg J, Moolman-Smook J, et al. Association between a catechol-Omethyltransferase polymorphism and obsessive-compulsive disorder in the Afrikaner population. J Affect Disord. 2001;65(1):61-5.

32. Karayiorgou M, Sobin C, Blundell ML, Galke BL, Malinova L, Goldberg P, et al. Family-based association studies support a sexually dimorphic effect of COMT and MAOA on genetic susceptibility to obsessive-compulsive disorder. Biol Psychiatry. 1999;45(9):1178-89.

33. Ohara K, Nagai M, Suzuki Y, Ochiai M, Ohara K. No association between anxiety disorders and catechol-0-methyltransferase polymorphism. Psychiatry research. 1998;80(2):145-8.

34. Tükel R, Gürvit H, Öztürk N, Özata B, Ertekin BA, Ertekin E, et al. COMT Val158Met polymorphism and executive functions in obsessive-compulsive disorder. J Neuropsychiatry Clin Neurosci. 2013;25(3):214-21.

35. Sampaio AS, Hounie AG, Petribu K, Cappi C, Morais I, Vallada H, et al. COMT and MAO-A polymorphisms and obsessivecompulsive disorder: a family-based association study. PloS one. 2015;10(3):e0119592.

36. Hosak L. Role of the COMT gene Val158Met polymorphism in mental disorders: a review. European Psychiatry. 2007;22(5):276-81.

37. Doyle AE, Yager JD. Catechol-O-methyltransferase: effects of the val108met polymorphism on protein turnover in human cells. Biochimica et Biophysica Acta (BBA)-General Subjects. 2008;1780(1):27-33.

38. Savage CR, Baer L, Keuthen NJ, Brown HD, Rauch SL, Jenike MA. Organizational strategies mediate nonverbal memory impairment in obsessive-compulsive disorder. Biol Psychiat. 1999;45(7):905-16.

39. White TP, Loth E, Rubia K, Krabbendam L, Whelan R, Banaschewski T, et al. Sex differences in COMT polymorphism effects on prefrontal inhibitory control in adolescence. Neuropsychopharmacology. 2014;39(11):2560.

40. Xie T, Ho S-L, Ramsden D. Characterization and implications of estrogenic down-regulation of human catechol-0methyltransferase gene transcription. Mol Pharmacol. 1999;56(1):31-8.

\section{Supplementary Files}

This is a list of supplementary files associated with this preprint. Click to download.

- Certificate.pdf 